\title{
Influence of Family Cohesion on Substance Use Disorders among the Youth in Selected Rehabilitation Centres in Nairobi County, Kenya
}

\author{
Alice Wangui Gikandi, Joyzy Pius Egunjobi (PhD), Joel Kiambi Muriithi (PhD) \\ Department of Psychology, The Catholic University of Eastern Africa
}

\begin{abstract}
This study investigated family dynamics and substance use disorders among the youth in selected rehabilitation centers in Nairobi County, Kenya. Using Yamane (1967) formula, a sample of 172 clients was obtained and selected randomly to take part in quantitative study. Another 12 clients who had stayed in rehabilitation centers for the longest time were purposively selected in order to provide qualitative data. Similarly, 10 parents were conveniently selected in order to provide qualitative data. Therefore the total sample size comprised of 196 respondents. Quantitative data was collected using FACES-IV, AUDIT, and DAST-10 questionnaires while qualitative data was collected using interview guides. Cronbach Alpha technique was run to test the reliability of FACES-IV, AUDIT, and DAST-10. FACES-IV scale was found to have a reliability coefficient of .723 , AUDIT had reliability of $\mathbf{. 8 6 1}$ while DAST-10 scale had a reliability coefficient of $\mathbf{. 8 1 2}$. Quantitative Data analysis was done using descriptive statistics and inferential statistics while qualitative data was analysed thematically backed by narratives from respondents. The study had the following findings, most respondents came from families with unhealthy cohesion (disengaged family cohesion $(\mathrm{Mean}=25.4545$; $\mathrm{SD}=9.3575)$, there was a strong negative and significant correlation between disengaged family cohesion and drug use disorder $(r=-0.527 ; P=$ 0.000).
\end{abstract}

\section{BACKGROUND}

$\mathrm{G}$ lobally, family dynamics have been linked to substance use disorders among the youth. For instance, a study done in Pakistan by Sobia Masood and Najam Us Sahar (2014) found that Poor communication within the family unit leads to children in the family indulging in drug abuse. The study also found that parents talk to their children about dangers of indulging in substance use but they were not firm in implementing the decisions involving the same. Similarly, a study examining youth's substance use disorder in United Kingdom by Roblyer (2016) suggested that youth reared in families characterized by a lack of familial obligations, emotional closeness, and support, were more likely to affiliate with substance use disorder and having peer relationships associated with more substance abuse. In addition, MacArthur, Hickman and Campbell (2016) study on the role of the family in structuring young people's alcohol use in England found that Parental attitudes and behaviours and the nature of communication are critical in leading young people's alcohol use. Initiation of alcohol use was frequently mediated by parents early in adolescence, with the home recounted as a primary site of early drinking experiences

However, it is important to note that although some family dynamics can lead youth to developing substance use disorders, the family can also provide resilience or protection against substance use disorders. For instance, a study by Catalina, Kopetz, and Lejuez (2015) reported that to some extent parents who successfully monitor their children, make them to have less opportunity to associate with friends who drink, as parents prohibit friendships with other youth who drink or prohibit their youth from being in situations which present opportunities to drink. It is therefore possible that parents' characteristics might interact with youths' friendship selection as both factors may impact one another in relation to youth friendship networks.

In Africa, the studies on family dynamics and substance use disorders among the youth are also scarce. However, the studies done also reveal that family dynamics such as parental communication, family cohesion and parental monitoring can also affect youth involvement in substance use. For instance an exploratory study by Muchiri and dos Santos (2018) on Family management risk and protective factors for adolescent substance use in South Africa. The specific protective, or risk effect of family management factors, varied according to substance. One of the factors that came out strongly and demonstrated either risk or protective effects on adolescent substance use was family cohesion, communication and monitoring.

In Kenya, the problem of substance use disorders among the youth has become a big threat to the society. The Government has tried put a lot of effort to eradicate this problem of substance use disorders among the youth by setting up rehabilitation centers which provide services such as treatment, counseling, and other supportive services. However, not much has been done on how family dynamics contribute to substance use disorders among the youth. This study therefore focused on exploring this gap by investigating how family dynamics contribute to substance use disorders among the youth in Nairobi County Kenya. 


\section{LITERATURE REVIEW}

Studies have been conducted on influence of family dynamics on drug abuse with varying findings. Kemjika and Ojiugo (2015) found that warm family environment leads to reduced time with friends which is potentially an important factor in preventing under-age smoking and substance use in later life. Nigeria The same study suggested that that parents need to provide their children with warmer family environment as home or provide them with family leisure times. This shows that if family dynamics are taken care of, the problem of substance use disorders among the youth can reduce.

According to Pergamit, Huang and Lane (2017) family interactions has a significant contribution in encouraging risk behaviours of adolescents, or in keeping away the adolescent from risky behaviours. Family cohesion describes relational interactions among family members with demonstrations of shared affection, support, commitment, and helpfulness (Rabinowitz et al., 2016). Families that have lower levels of cohesiveness tend to have and model ineffective communication; they are less able to support each other during times of distress and are particularly less effective in decreasing distress in their adolescent (Rabinowitz et al., 2016).

Stronger levels of cohesion are beneficial for youth development of socially appropriate responses and the management of social tensions. Family cohesion helps adolescents with negative emotional reactivity. It helps to learn how to better regulate their state of emotions and to develop more positive perceptions of others, decreasing their negative responses based on anger or fear when threats are perceived (Rabinowitz et al., 2016).

Surprisingly, Henneberger and colleagues (2016) examined 364 inner city adolescent boys (54\% AfricanAmerican and $40 \%$ Hispanic) and it was inconsistent with other findings on family cohesion being a protective factor as a strong relationship was established between highly cohesive families and peer violence and delinquency. A possible explanation to this outcome was perhaps that parents with intentions to protect their child via family cohesiveness left their adolescent without the critical refusal skills needed to avoid the influence of violent peers.

Elam, Chassin and Panndika (2018) conducted a study to examine adolescents' polygenic risk scores for aggression in evocative $r$ GEs underlying aggression and family cohesion during adolescence, their contributions to alcohol use in early adulthood. The sample size $(n=479)$, comprised of Mexican American and European American. The study results suggested that an evocative $r \mathrm{GE}$ between polygenic risk scores, aggression, and low family cohesion, with aggression contributed to low family cohesion over time. Further the study found that greater family cohesion was associated with lower levels of alcohol use in early adulthood and this association was stronger for Mexican American adolescents compared to European American adolescents.

Daniel, Shek, Zhu, Dou and Chai (2020) examined the concurrent and longitudinal influences of paternal and maternal factors on the levels of and changes in substance use among early adolescents. One of the factors examined was cohesiveness in the family and substance use among the adolescents. Data was collected from 2,669 junior high school Chinese students in Hong Kong. The study found that the quality of parent-adolescent relationship were negative predictors of the initial levels of substance use. In terms of gender, higher levels of quality of mother-adolescent relationship predicted a slower rate of increase in adolescent substance use compared to father-adolescent relationship.

Gebremariam and Sandhu (2020) investigated the impacts of family environment on substance use among Kotebe Metropolitan University Students in Ethiopia. Institutional based Cross-sectional explanatory research design was used for this study. The sample size comprised of 351 students. Subscales of Family Environment Scale which were measured were family cohesion, family communication and family conflict. Drug use Questionnaire (DAST-20) developed by Skinner (1982) was used to measure the possible involvement of drugs during the past 12 months by the respondents. The Scale of Family Environment developed by Moos and Moos (1981) which assesses an individual's perceptions of the family social climate (family cohesion, conflict, and expressiveness) was used. Multiple Linear Regression Analyses was computed to examine the link between family cohesion, family conflict, and family communication and substance use.

\section{METHODS}

\section{Research Design}

This study adopted a mixed methods embedded design. In this design, one data set provides a supportive, secondary role in a study based primarily on the other data type (Creswell, 2014). The premises of this design are that a single data set is not sufficient, that different questions need to be answered, and that each type of question requires different types of data. This design was particularly useful when the researcher needed to embed a qualitative component within a quantitative design. Through this design, quantitative data, and qualitative data was collected concurrently and integrated during data analysis, and interpretation to answer the research questions.

\section{Location of the Study}

The study was carried out in selected rehabilitation centres Nairobi County, Kenya. Nairobi County is one of the 47 Counties in Kenya. It is the most populous and largest city of Kenya with a cosmopolitan set-up. Almost all the tribes in Kenya are represented in the city. The city also houses all the organs of the government and it is the headquarters of almost all the organizations in the country. It 
is also the economic power house of the country. It borders Machakos, Kiambu, and Kajiado Counties. Because of its cosmopolitan nature, Nairobi has also been found to be both a destination and a conduit for hard drugs. Drugs of all types are sold in the city's black market. This is true given the fact that the city is highly populated and hence chances of finding a ready market for drugs are high. There have been incessant reports of incidences of drug impounding by police. The youth access these substances easily as they get money from their parents or from employment to procure various substances.

\section{Target Population}

The target population for this study was 303 youth admitted in 18 rehabilitation centers in Nairobi and their parents/guardians. Usually, these rehabilitation centers do have more clients than these but the numbers were affected by the Covid 19 pandemic. However, the population targeted and identified had salient characteristics hence the study was carried out. The population in the rehabilitation centers may change from time to time due to new entrants as well as discharges on daily basis. Some rehabilitation centres have youths admitted while others visit from home, and some centres have more clients than others

\section{Sample Size}

According to Kamangar and Islami (2013), a sample size is a statistical representation of the population of interest. Therefore, choosing a sample is a key feature of any research undertaking. A sample allows generalization of findings to the entire population under the study. Yamane (1973) sample size formula was used to obtain the sample size for the study.

$$
\begin{aligned}
\mathrm{n} & =\frac{\mathrm{N}}{1+(\mathrm{e})^{2} \mathrm{~N}} \\
& =\frac{303}{1+(0.05)^{2}(303)} \\
& =172
\end{aligned}
$$

This gave a sample size of 172 respondents.

The sample size of the youth was accessed through the office of the administrators of the rehabilitation centers. Since the population was homogeneous in terms of drugs use, participants for this study were selected by simple random sampling. The study excluded any participant who did not fall in the category of youth.

\section{RESULTS}

\section{Respondents' Family Cohesion}

The study sought respondents' family cohesion. Family cohesion refers to the emotional relationships and sense of togetherness that family members have toward one another (Laursen \& Mooney, 2008). Family cohesion was measured using FACES IV standardized tool developed by Olson (2010). The tool has 62 items and it measures family flexibility, family cohesion and family communication. The respondents were provided with 5-point Likert scale provide and were asked to indicate the degree to which they agree or disagree with each statement. From the 62 items, only family cohesion is measured using items $1,3,4,7,9,10,13,15,16,19,21,22,25,27,28,31,34,35,37,39$ and 40. During scoring, items measuring family cohesion were transformed into three subscales; balanced cohesion represented by items $1,7,13,19,25,31$ and 37 . The second sub scale of family cohesion was disengaged which was represented by items 3,9,15,21,27,35 and 39. The last sub scale of family cohesion was enmeshed which was represented by items $4,10,16,22,28,34$ and 40. During scoring and interpretation, all the items in each subscale were computed. Each subscale had 7 items and the Likert scale was scored 5-strongly agree, 4- agree, 3 undecided, 2disagree and 1- strongly disagree. The scores were computed where family cohesion was measured in terms of mean with the lowest possible mean being 7 and the highest possible mean being 35 . The findings were presented as shown in table 1 below.

Table 1: Respondents' Family Cohesion

\begin{tabular}{|c|c|c|c|c|c|}
\hline & $\mathrm{N}$ & $\begin{array}{c}\text { Minimu } \\
\mathrm{m}\end{array}$ & $\begin{array}{c}\text { Maximu } \\
\mathrm{m}\end{array}$ & Mean & $\begin{array}{c}\text { Std. } \\
\text { Deviatio } \\
\mathrm{n}\end{array}$ \\
\hline $\begin{array}{c}\text { Family } \\
\text { Cohesion } \\
\text { (Disengage } \\
\mathrm{d} \text { ) }\end{array}$ & $\begin{array}{c}13 \\
2\end{array}$ & 7.00 & 35.00 & $\begin{array}{c}25.454 \\
5\end{array}$ & 9.35750 \\
\hline $\begin{array}{c}\text { Family } \\
\text { Cohesion } \\
\text { (Balanced) }\end{array}$ & 13 & 7.00 & 35.00 & $\begin{array}{c}16.901 \\
5\end{array}$ & 8.27657 \\
\hline $\begin{array}{c}\text { Family } \\
\text { Cohesion } \\
\text { (Enmeshed) }\end{array}$ & $\begin{array}{c}13 \\
2\end{array}$ & 7.00 & 35.00 & $\begin{array}{c}15.136 \\
4\end{array}$ & 6.38076 \\
\hline $\begin{array}{c}\text { Valid N } \\
\text { (listwise) }\end{array}$ & 13 & 2 & & & \\
\hline
\end{tabular}

The findings in Table 1 indicate that most families recorded unhealthy cohesion with disengaged family cohesion (Mean $=25.4545 ; \mathrm{SD}=9.3575)$ followed by enmeshed family cohesion $(\mathrm{Mean}=15.1364 \mathrm{SD}=6.38076)$. The healthy family cohesion that is balanced cohesion had Mean=16.9015 SD 8.2765 which is slightly above the cut of average of 14 . From these results it could be concluded that most families that took part in this study were dysfunctional in terms of cohesion. The disengaged families for instance lacks connectedness among members while enmeshed families have emotionally entangled members with low levels of individuation.

\section{Family Cohesion and Substance Use Disorders among the} Youth

The study sought to find out whether there was relationship between Family cohesion and Substance Use Disorders among the Youth. Pearson correlation analysis was used and findings presented in Table 2 below. 
Table 2: Influence of Family cohesion on Substance Use Disorders among the Youth

\begin{tabular}{|c|c|c|c|c|c|}
\hline & & $\begin{array}{l}\text { Family Cohesion } \\
\text { (Balanced) }\end{array}$ & $\begin{array}{l}\text { Family Cohesion } \\
\text { (Disengaged) }\end{array}$ & $\begin{array}{c}\text { Family } \\
\text { Cohesion } \\
\text { (Enmeshed) }\end{array}$ & Drug Use Disorder \\
\hline \multirow{3}{*}{ Family Cohesion (Balanced) } & Pearson Correlation & 1 & & & \\
\hline & Sig. (2-tailed) & & & & \\
\hline & $\mathrm{N}$ & 132 & & & \\
\hline \multirow{3}{*}{ Family Cohesion (Disengaged) } & Pearson Correlation & $-.527^{* *}$ & 1 & & \\
\hline & Sig. (2-tailed) & .000 & & & \\
\hline & $\mathrm{N}$ & 132 & 132 & & \\
\hline \multirow{3}{*}{ Family Cohesion (Enmeshed) } & Pearson Correlation & $.767^{* *}$ & $-.562^{* *}$ & 1 & \\
\hline & Sig. (2-tailed) & .000 & .000 & & \\
\hline & $\mathrm{N}$ & 132 & 132 & 132 & \\
\hline \multirow{3}{*}{ Drug Use Disorder } & Pearson Correlation & $-.315^{* *}$ & .057 & $-.304^{* *}$ & 1 \\
\hline & Sig. (2-tailed) & .000 & .514 & .000 & \\
\hline & $\mathrm{N}$ & 132 & 132 & 132 & 133 \\
\hline
\end{tabular}

The findings in table 2 indicate that there was a strong negative and significant correlation between disengaged family cohesion and drug use disorder $(\mathrm{r}=-0.527 ; \mathrm{P}=0.000)$, strong positive and significant correlation between enmeshed family cohesion and drug use disorder $(\mathrm{r}=0.767, \mathrm{p}=0.000)$ and weak positive and significant relationship between balanced family cohesion and drug use disorder $(r=-0.315$, $\mathrm{p}=0.00)$. This implies that the more healthy families are the less drug use disorder is likely to increase. On the other hand an increase in family enmeshment would also lead to a corresponding increase in drug use disorder meaning that much family control of members would increase drug use. However an increase in chaotic family flexibility also would lead to an increase in drug use disorder.

\section{DISCUSSION}

These findings were in support of the Dutraérick, Neveslarissa, Limamonalisa and Gomes et al. (2020) crosssectional study findings. Their study was carried out to evaluate the association between number of cavitated dental caries among adolescents who use drugs and family cohesion among adolescents aged 15 to 19 years from Campina Grande, Brazil. The study found that a large portion of the adolescents came from disengaged family ( $\mathrm{n}=344$ 46.1\%) followed by those who came from families which were separated $(n=26635.7 \%)$, those whose families were connected $(n=121 \quad 16.2 \%)$ and those whose families were enmeshed $(n=152.0 \%)$.

Lastly, Wahaba et. al (2021) study findings, were similar to the findings of this study. They conducted a cross sectional survey study on the relationship of lifetime substance-use disorder with family functioning, childhood victimization, and depression, among juvenile offenders in Malaysia.
With respect to family functioning where sub scales such as family cohesion, family flexibility and family communication patterns which were measured using FACES IV scale, the study had several findings. The mean scores of the balanced scales were higher than those of the unbalanced scales among the participants at 25.22 and 20.74, respectively. For instance, the cohesion ratio [balanced cohesion/(disengaged + enmeshed/2)], flexibility ratio [balanced flexibility/(rigid + chaotic/2)] and total circumplex ratio (cohesion ratio + flexibility ratio/2) exceeded 1 indicating a balanced family functioning for the participants. Further, the level of family cohesion and flexibility for most of the respondents who had been staying with their biological parents before they were admitted to the detention centre, were found to be moderately balanced.

These study findings were corroborated by Elam, Chassin and Panndika (2018) study findings. Their study was conducted to examine adolescents' polygenic risk scores for aggression in evocative underlying aggression and family cohesion during adolescence, their contributions to alcohol use in early adulthood. The study found that greater family cohesion was associated with lower levels of alcohol use in early adulthood and this association was stronger for Mexican American adolescents compared to European American adolescents

Daniel, Shek, Zhu, Dou and Chai (2020) study on the concurrent and longitudinal influences of paternal and maternal factors on the levels of and changes in substance use among early adolescents had contrary findings to this study. Daniel, Shek, Zhu, Dou and Chai (2020) study found that the quality of parent-adolescent relationship were negative predictors of the initial levels of substance use. Likewise, Gebremariam and Sandhu (2020) study findings on the impact 
of family environment on substance use among Kotebe Metropolitan University Students in Ethiopia had different findings. The study findings revealed that family cohesion and family communication were inversely related with substance usage among participants. This inverse association of family cohesion and family communication with that of substance usage implied that, a cohesive family environment plays a role in preventing the students from engaging in substance use.

In addition, the findings of the study by Kopak, Chen, Haas and Gillmore (2012) on the importance of family factors to protect against substance use related problems among Mexican heritage and White youth showed that the association of lower probability of substance and alcohol use problems and good family cohesion among Mexican heritage and white youths in the United State.

Another study in support of these findings was by Patel (2017) which was conducted to examine whether family cohesion mediates the relationship between types of conversations and adolescent substance use. Findings of Patel study depicted that an increase in criticism during family meals was correlated to marijuana use and cocaine use. On the other hand, conversations that involved parental monitoring was associated with a decrease in cocaine usage with results showing that parental monitoring was a potential protective factor for substance use. Further, Patel study found that adolescents who had conversations during family meals that involved parental monitoring were less likely to initiate cocaine use.

In addition, Caetano, Vaeth and Canino (2017) study while examining the association between family cohesion/pride, drinking, binge drinking, and DSM-5 alcohol use disorder (AUD) in Puerto Rico had similar findings with this study. The study findings revealed that family cohesion/pride was not associated with the average number of drinks consumed per week but was associated with binge drinking among men. Further, the study found that family cohesion/pride was also associated with DSM-5 AUD. This meant that respondents with low $(\mathrm{OR}=2.2,95 \mathrm{CL}=1.21-$ $3.98 ; \mathrm{p}<.01)$ and medium $(\mathrm{OR}=1.88 ; 95 \mathrm{CL}=1.12-3.14 ; \mathrm{p}$ $<.01)$ family cohesion/pride were more likely to have a positive diagnosis of DSM-5 Alcohol Use Disorder than those with high family cohesion/pride. With these findings, the study concluded that higher family cohesion/pride may have a protective effect against DSM-5 Alcohol Use Disorder.

Lastly, a study by Boyd, Perkins, Greenberg and Stevens (2014) also corroborated the findings of this study. The utilized a Qualitative and Quantitative Approach to Examine Substance Use and Parental Communication among African American Youth. Pearson correlation analysis was carried out to find the relationship between substance use and family cohesion and family communication of the young adults. The study found a statistically significant relationship, $\mathrm{r}(89)=-.281, \mathrm{p}<.001$ (two-tailed) which indicated that the more cohesive a family is, the less likely the participant would be to engage in substance abuse.

\section{CONCLUSION}

The study points to the need for enhancing family relationship quality as a preventive measure for drug abuse among youth in Nairobi County, Kenya. It is important to note that when a family member in any given family becomes addicted to drugs the entire family is affected emotionally. The prevention and treatment of drug abuse can therefore be enhanced by involving the entire family and not just waiting to take the affected person to rehabilitation centers.

\section{REFERENCES}

[1] Boyd K., Perkins, P, Green B, Stevens L (2014). Utilizing a Qualitative and Quantitative Approach to Examine Substance Use and Parental Communication among African American Youth. Department of Psychology, Virginia State University, Petersburg, USA.

[2] Caetano, R., Vaeth, P., \& Canino, G. (2017). Family cohesion and pride, drinking and alcohol use disorder in Puerto Rico. The American Journal of Drug and Alcohol Abuse, 43, 87 - 94.

[3] Creswell, J. W. (2014). Research Design: International Student Edition. Qualitative, Quantitative and mixed methods Approaches. (4thEd.). London: Sage Publications

[4] Daniel T. L. Shek, Zhu, X. Dou, D. \& Chai, W. (2020) Influence of Family Factors on Substance Use in Early Adolescents: A Longitudinal Study in Hong Kong, Journal of Psychoactive Drugs, 52:1, 66-76

[5] Elam, K., Chassin, L., \& Pandika, D. (2018). Polygenic risk, family cohesion, and adolescent aggression in Mexican American and European American families: Developmental pathways to alcohol use. Development and Psychopathology, 30(5), 1715-1728

[6] Gebremariam, K.T \& Sandhu. (2020). Family Environment and Substance Use Among University Students. International Journal of Scientific \& Technology Research, 9( 2);1530-1535K

[7] Kemjika O.G. \& Ojiugo A.B. (2015). Influence of family dysfunction on drug use of adolescent students of unity schools in south-south zone Nigeria. Journal of Psychological Research (EJPR). 1

[8] Kopetz, C. E., Collado, A., \& Lejuez, C. W. (2015). When the end (automatically) justifies the means: Automatic tendency toward sex exchange for crack cocaine. Motivation Science, 1(4), 233243. https://doi.org/10.1037/mot0000025

[9] Laursen, B., \& Mooney, K. S. (2008). Relationship network quality: Adolescent adjustment and perceptions of relationships with parents and friends. American Journal of Orthopsychiatry 78(1):47-53

[10] MacArthur, Hickman \& Campbell (2016). A qualitative investigation of the role of the family in structuring youn people's alcohol use. European Journal of Public Health, Volume 26, Issue 1, February 2016, Pages 102-110,

[11] National Authority for the Campaign Against Drug Abuse. (2017). Rapid Situation Assessment of Drugs Substance in Kenya. Nairobi: NACADA.

[12] Olson, D. (2011). FACES IV and the circumplex model: Validation study. Journal of Marital and Family Therapy, 37(1), 64-80

[13] Patel, S. (2017). Substance Use: Family Meals, Conversations, and Family Cohesion. A Thesis faculty of the Department of Graduate and Professional Studies in Education California State University, Sacramento

[14] Pergamit,M, Huang L. and Lane J. (2017) Does religion affect alcohol and tobacco use among students at North-West University, South Africa. Journal of American College Health

[15] Robylyer, M.D. (2016) Integrating educational technology into teaching (7th Edition). New Jersey: Pearson Education Inc 
[16] Sobia M. \& Najam U. S. (2014) An exploratory research on the role of family in drug addiction, Health Psychology and Behavioral Medicine: 2:1, 820-832

[17] Yamane, T. (1973). Statistics, An Introductory Analysis, 2nd Ed., New York: Harper and Row. 